\title{
يوم دراسي حول: "مدارس ومعاهد جمعية العلماء المسلمين الجزائريين"
} نظمته جمعية العلماء المسلمين ومركز الفنون والثقافة

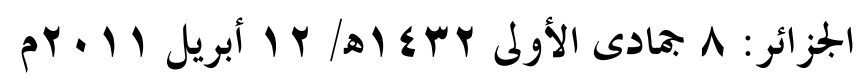

مولود عويمر

نظمت جمعية العلماء المسلمين الجزائريين، ومركز الفنون والثقافة يومـــاً دراســيـاً

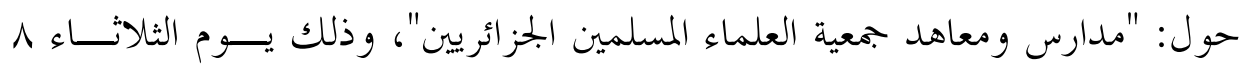

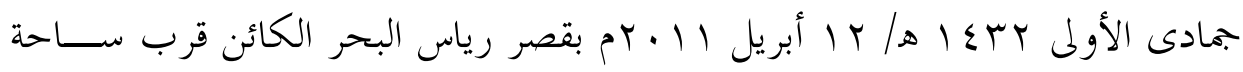
الشهداء بالجز ائر العاصمة.

بدأت أعمال اليوم بجلسة افتتاحية؛ إذ رحب الأستاذ جمال ســعلداوي مستشـــار

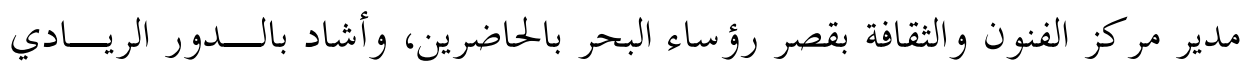

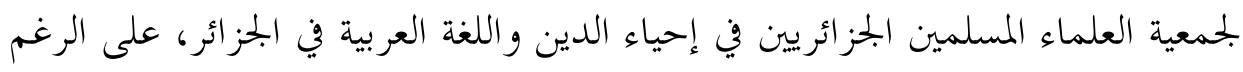
من كل مثبطات سلطة الاحتلال الفرنسي.

وتحدث الدكتور مولود عويمر المنستق العلمي للنشاط عن موضوع هـــذا اللقــــاء

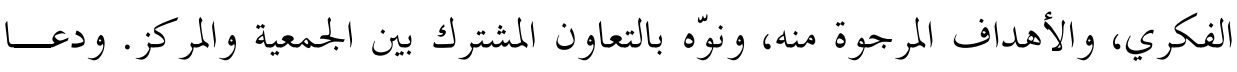

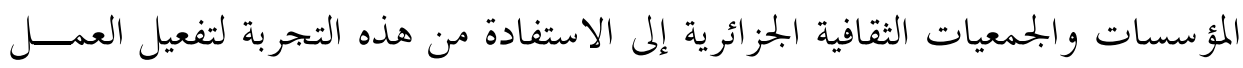
الفكري في البلاد.

وتحدث الشيخ محمد الأكحل شرفا؛ النائب الأول لرئيس جمعية العلماء المســـلمين الجزائريين عن أفكار هذه الجمعية ورجاها، واستحضر ذكرياته عن أستاذه الشيخ عبد

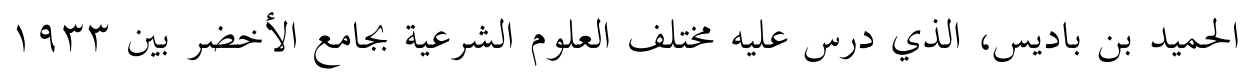
$.19 \leq \cdot 9$

" دكتوراه دولة في التاريخ من جامعة باريس، أستاذ التعليم العالي في كلية العلوم الإنسانية، جامعة الجزائر. البريـــــا. الإلكتروني: Mouloud1968@yahoo.fr 
تناولت الجلسة العلمية الأولى محور "التربية و التعليم في المشروع الإصلاحي لجمعية العلماء"، وترأسها الأستاذ التهامي بجوري؛ أمين المال في جمعية العلمــــاء المســلمين. وبدأت الجلسة بورقة الدكتور عبد الرزاق قسوم أستاذ الفلسفة بجامعة الجزائر ب المعنونة

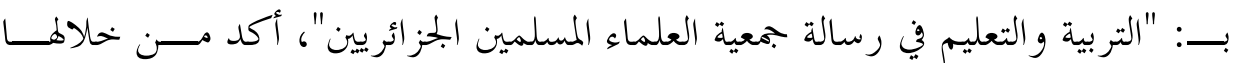

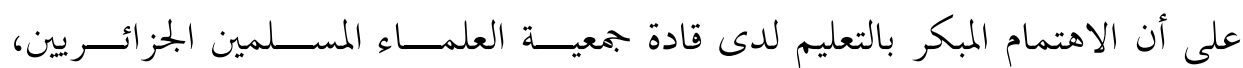
وإصرارهم على ربطه بالتربية، هما سرّ بجاح رسالتهم ودعوقهم وتوفيقهم في إفشـــال المشروع الثقافي الاستعماري في الجز ائر المدعّم بكل الوسائل. و جاءت ورقة الأستاذ مراد قبال المدرس بجامعة البليدة بعنوان: "النظام التعليمــي لمدارس جمعية العلماء"، ورأى فيها أن جمعية العلماء كانت تؤمن بأن نشر الإصــلاح

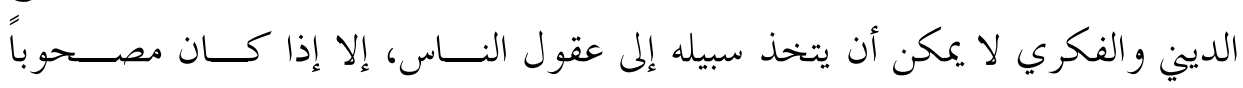
بالتعليم. ومن هنا كان فتح مدارس عربية حرة في مختلف المدن والقرى الجزائرية. وقدم المحاضر بعض الإحصائيات التي تئ كد ارتفاع عدد المدارس و التلاميذ و المعلمين بشكل مطرّد. وقد استمدت هذه المدارس مناهجها و بر ابجها من مبادئ جمعية العلماء. وعرض الأستاذ محمد العلمي السائحي؛ المكلف بالإعلام في جمعية العلماء، الابحاه الإصلاحي لمدارس جمعية العلماء، وأشار إلى بعض ملامحها التنويرية. وذلك في ورقتــه المعنونة بــ: "الفكر الإصلاحي و التنويري لمدارس جمعية العلماء".

وتناولت الجلسة العلمية الثانية محور: "نماذج من مدارس ومعاهد جمعية العلماء".

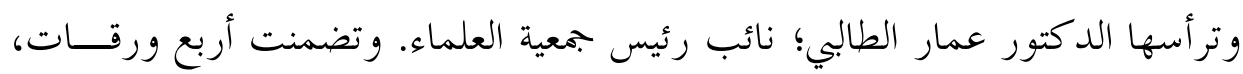
بدأها الدكتور مولود عويمر؛ المكلف بالتراث والبحث العلمي في الجمعية بورقة عــن "الجحامع الأخضر في عصر الإمام ابن باديس". و بيّن فيها ســيرورة المســـد ودوروه في

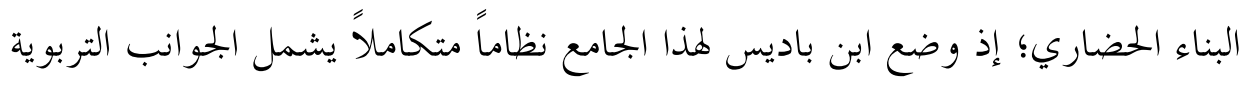

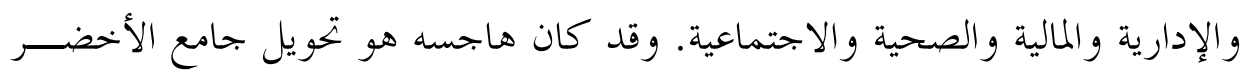
إلى كلية إسلامية يُعترَف بشهاداها كبقية الكليات الإسلامية في العالم الإسلامي. 


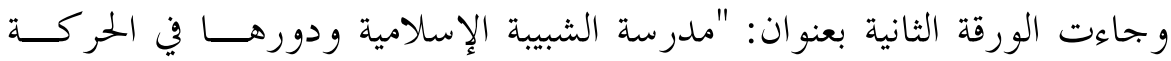

الإصلاحية" للأستاذة عفاف زقور من جامعة الجزائر.ب وتحدثت فيها عــن مدرســة الشبيبة الإسلامية، ودورها الرائد في التربية والتعليم، لا سيما في المدة التي أشـــــت رفت عليها جمعية العلماء المسلمين الجزائريين؛ إذ أدارها الشيخ محمد العيد آل خليفة لفتـــرة طويلة، ودرّّ فيها بحموعة من الأساتذة الأفذاذ أمثال: فرحات بن الدراجي، و باعزيز ابن عمر، و محمد الهادي السنوسي، و جلول البدوي، وعبد الرحمن الجيلالي.

و لم تقتصر هذه المدرسة على تعليم البنين و البنات اللغة العربية، وبعـــض العلـــوم الشرعية، بل تقوم أيضاً بتعليم البنات فنون التدبير المنــزلي.

وتكلم الأستاذ عبد الباسط قلفاط، من المركز الجامعي بخميس مليانة، عن موقــع

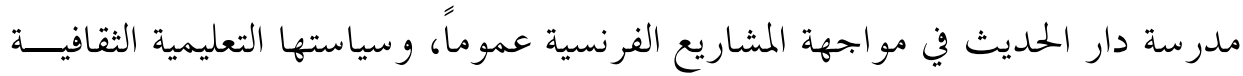
خاصة، وذلك في ورقته المعنونة: "دار الحديث بتلمسان ورسالة التعليم والإصــلاح". ورأى الباحث أن هذه المؤسسة حققت خطوات مهمة في تطهـير عقائســد الإســالام وعباداته من أضرار الابتداع و الممارسات السلبية للطرق الصوفية، كما كان لها الدور الرائد في ميادين التربية والتعليم وتوحيد الجهود لمو اجهة الاستعمار الفرنسي. وجاءت ورقة الباحث في التاريخ الأستاذ سعيد بودينة المعنونة بــــــ "مدرســـة التربية و التعليم بقسنطينة ورسالة التربية والإصلاح". لتكشف عن الـــدور التربـــوي

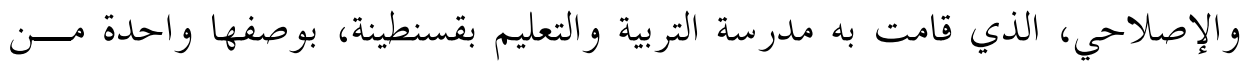
أبرز قلاع التربية والإصلاح في الجزائر؛ إذ شجعت على تعليم البنات بحاناً، وتكوينهن

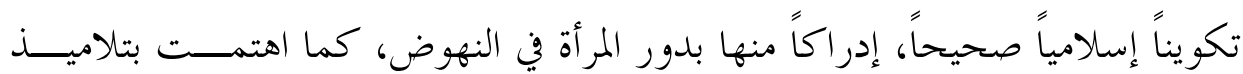

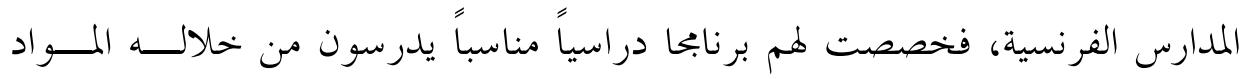

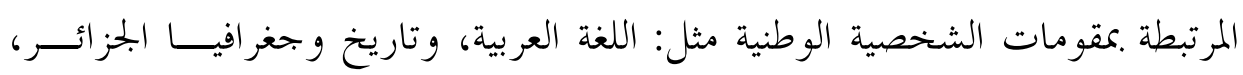
و التاريخ الإسلامي، حتى يرتبط هؤلاء منذ الصغر بكويتهم الوطنية وانتمــائهم العـــــي 
و تعرضت الجلسة العلمية الثالثة إلى "البعد التنويري و الوطني لمدارس ومعاهد جمعية

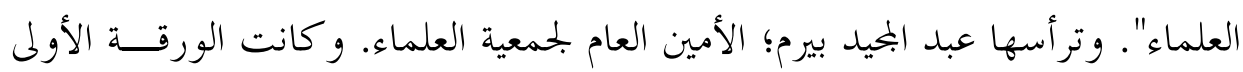

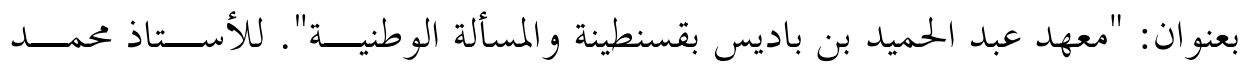
دراوي من المركز الجحامعي في خميس مليانة. وتحدث فيها عن معهد عبد الحميـــد بــنـ

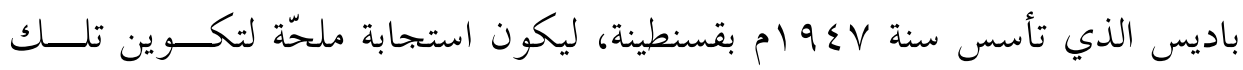

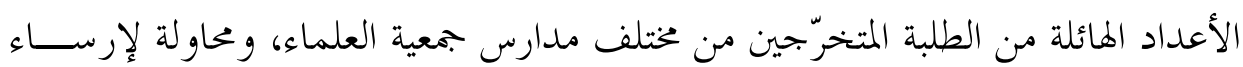
تعليم متميّز يحاكي المدارس الكبرى في المشرق والمغرب، كالأزهر و الزيتونة والقرويّين.

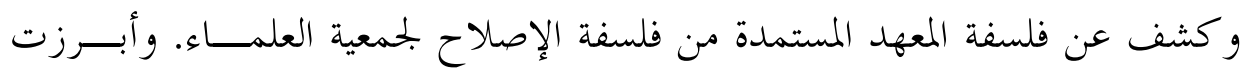
الورقة أن الوثائق والشّهادات الكثيرة في هذا المجال أشارت إلى مساهمة طلبة المعهد في الثورة التحريرية بقيادة العمل الثوري في مختلف الولايات و المناطق.

وتطرقت الدكتورة يمينة بشي؛ أستاذة الأدب العربي بجامعة الجزائســــ إلى جهــود

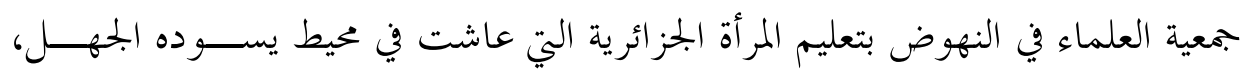
و الظلام، واستبداد المستعمر. وذلك في ورقتها المعنونة بـــ "جهود جمعية العلمــاء في

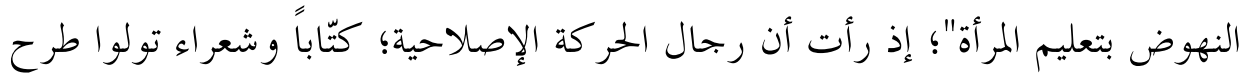

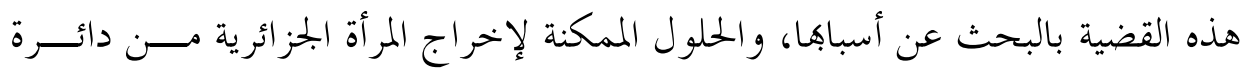
التخلف و الجهل، من خلال برنامج عمل ورؤية خاصة في طبيعة ونوعية التعليم الذي

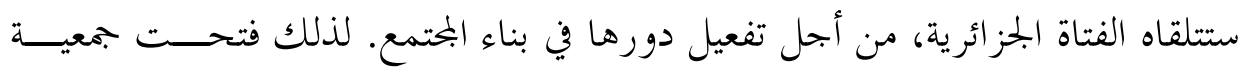

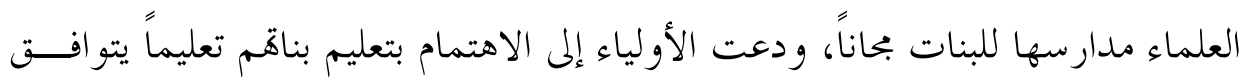
مع قيمها و تقاليدها و فطرةا.

وتحدث الدكتور لزهر بديدة؛ أستاذ التاريخ المعاصر بجامعة الجزائرب عن مكانــة الوعي الوطني في مدارس جمعية العلماء. في ورقته المعنونة بـــ "مكانة الوعي الوطني في

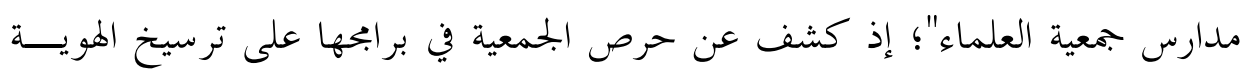
العربية الإسلامية للتلاميذ، وتوجيهم نخو حب الوطن بدراسة تاريخهم و التعرف علـىى 
أبطاله، والاعتزاز برموزه المادية والمعنوية. وقد تفطنت مبكرة الســلطة الاســتعمارية لذلك، فمارست مضايقات على هذه المدارس بسن قو انين بححفة، و اعتقلت بمو جبـــها العديد من المعلمين بذريعة التدريس دون رخصة.

وناقشت الندوة الفكرية التي أدارها الدكتور مولود عويمر الإشكالية الآتية: كيف

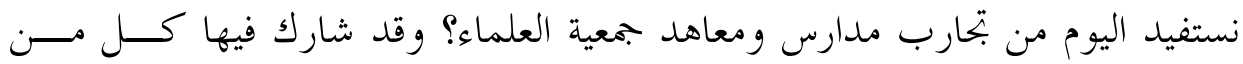

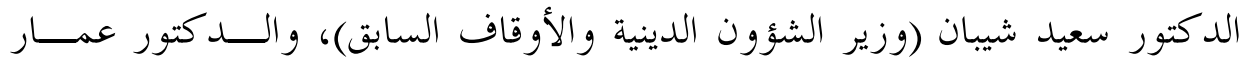
الطابي و الدكتور عبد المجيد بيرم. وأشار المتداخحلون إلى بناح بتحارب مــــارس جمعيـــة العلماء بفضل مناهجها الواضحة والمتو افقة مع قيم الجزائريين، و المتجاوبة مع آمالهم في

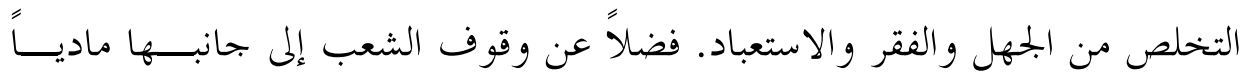

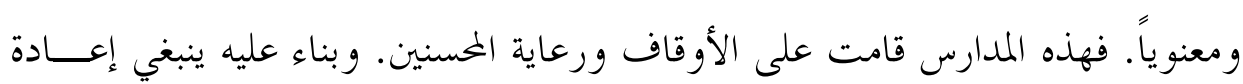
إحياء تلك الأسس والقيم لبناء جيل المستقبل القادر على صنع هضة جديدة.

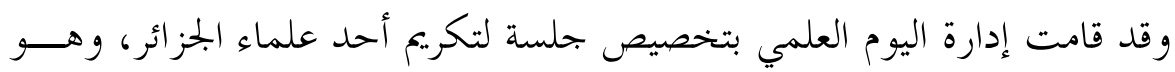
الأستاذ محمد حسن فضلاء؛ إذ ألقيت فيها كلمات تناولت مناقب المحتفى به، و تناوب على إلقاء الكلمات كل من الأستاذ زبير طو البي؛ المكلف بالتنظيم في جمعية العلمـــاء. وزوجة الأستاذ محمد؛ إذ شكرت المنظمين على هذه الفعالية، وأثنى كل من الأستاذين عبد الحميد فضلاء وباديس فضلاء على الجهود التي قام بها عمهما في بحـــال التربيـــة و التعليم. وقام الدكتور عمار الطابي بتسليم العائلة شهادة تكريم للجهود الحضارية التي قام بها الأستاذ محمد فضلاء. وقد رشح عن هذا اليوم العلمي أفكار عديدة تمثلتها التوصيات الآتية: - توجيه الباحثين إلى إبحاز دراسات أكاديمية حول مدارس ومعاهد جمعية العلماء - دعوة المشرفين على البرامج التعليمية والمناهج التربوية إلى الاستفادة من بحارب مدارس جمعية العلماء وإبخاز اتها المختلفة 
تقارير مؤتمرات

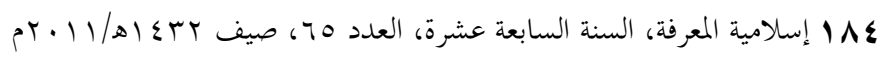

- إعداد وإبحاز أفلام وأشرطة وثائقية، تسهم في التعريف بمدارس ومعاهد جمعيــة

العلماء في داخل الوطن وخحارجه

- ضرورة التعاون بين جمعية العلماء والجمعيات الثقافية والمؤسسات العلمية لمزيد

من النشاط الثقافي و الحر اك الفكري

- الدعوة إلى عقد يوم دراسي عن نوادي جمعية العلماء ورســالتها الإصــلاحية

والتنويرية

- طبع أعمال اليوم العلمي في نسخ ورقية ورقمية، وتوزيعها علــى المؤسســات

الثقافية و الجامعية لتعم الفائدة. 